\title{
Dilemas e desafios da função docente na sociedade atual: os sentidos da mudança
}

\section{Dilemmas and challenges of the teacher's function in the contemporary society: the meanings of the change}

\author{
Regina Cely de Campos Hagemeyer ${ }^{*}$
}

\begin{abstract}
RESUMO
A abordagem propõe a constatação das exigências de mudança na atualidade, decorrentes do quadro complexo em que se dá a educação escolar hoje para pensar os rumos da atuação/formação do professor. Procurou-se analisar as questões presentes nas tensões vividas pelos docentes no processo pedagógico (curricular), analisando os reflexos do pensamento moderno e pós-moderno na trajetória docente. Em função dessa proposta, são apresentados resultados da investigação desenvolvida com alunos(as) da disciplina de Currículos e Programas do Curso de Pedagogia e posteriormente aprofundada em Projeto de Pesquisa (Prolicen-UFPR) no ano de 2001. Os pesquisadores investigaram professores de escolas públicas de Curitiba e região metropolitana. Buscou-se a leitura de significados, necessidades e opções presentes na condução e moldagem das práticas docentes na atualidade, considerando o conceito de habitus de BOURDIEU e as possibilidades de análise abertas por SACRISTÁN, GIROUX e GRAMSCI. Procurou-se desenredar a função docente da profusão de exigências que lhe são postas hoje, numa contribuição ao redirecionamento das propostas prescritivas de mudança e, sobretudo, de formação do professor.
\end{abstract}

Palavras-chave: função docente, sentido da mudança, modernidade, pósmodernidade.

* Doutoranda em Educação na Universidade de São Paulo (USP). Professora do Departamento de Planejamento e Administração Escolar da Universidade Federal do Paraná (UFPR). E.mail: regicely@terra.com.br 


\begin{abstract}
This approach presents a panorama of the complex situation of education in schools nowadays, and the need for changes in the formation/ performance of the teacher. Strains experienced by teachers during the pedagogical process are analyzed taking into account reflections of modern and postmodern thinking. According to this proposal, the results of the investigation developed by graduate and undergraduate students in a discipline of "Curriculum and Programs" in the Course in Pedagogy, and later deepened in a Research Project (Procelin-UFPR), in 2001, are presented here. The researchers investigated teachers from public schools in Curitiba and Great Curitiba. The meanings, needs and options related to the teacher's practice nowadays were understood considering Bordieu's concept of habitus, and the analytic possibilities opened by SACRISTÁN, GIROUX and GRAMSCI. This article tries to disentangle the teacher's work from the many demands imposed nowadays, concurring to a redirection in the prescriptive proposals of changes and specially in the ones referring to the formation of teachers.

Key-words: teacher's function, meanings of change, modernity, postmodernity.
\end{abstract}

\title{
Introdução
}

Ao refletir sobre a função do professor na atualidade, deparamo-nos com a dificuldade de combinar os muitos fatores que dizem respeito à formação humana. O contexto atual, em que os problemas político-econômicos estão aliados à vertiginosa evolução científica e tecnológica, reflete-se em mudanças nas formas de ser e viver dos homens em todos os níveis, desconcertando a quem tem a profissão de ensinar/formar crianças e adolescentes.

Parece que a escola deve mudar e espera-se essa mudança principalmente no foco de atuação do professor. Para HARGREAVES (1994), a escola se constitui hoje em um receptáculo político, no qual se depositam os problemas insolúveis da sociedade. Nas imposições de revisão curricular e outras, os professores devem buscar a reconstrução de culturas e identidades nacionais, sempre em contexto de recessão financeira. Experimentam uma sensação de intolerável culpabilidade e trabalho intensificado. Observa-se que, mesmo frente a cada vez mais cargas às estruturas e responsabilidades para a função, 
os professores de alguma forma vêm respondendo às expectativas e exigências da mudança. Cabe então perguntar: Quais as tensões e conflitos do professor frente às mudanças sociais e novas propostas pedagógicas? Quais os processos de criação e construção cotidianos no desenvolvimento do trabalho pedagógico neste contexto? Quais as exigências para sua formação no desenvolvimento deste trabalho?

Em função dessas questões, procuramos discutir os dilemas da função docente hoje, buscando no próprio professor e no seu processo de produção os sentidos da mudança. Partimos de uma reflexão sobre a natureza do trabalho pedagógico, para não perder de vista os objetivos educacionais que lhe são próprios e procuramos considerar três campos que caracterizam o trabalho docente: o da competência científica, o técnico-didático e o humano-social, que também circunscreve a questão cultura. Esses serão tratados de forma sempre inter-relacionada e chamando a atenção ao último, como essência do trabalho pedagógico, que pode apontar necessidades urgentes da função e formação docente na atualidade.

Para esse encaminhamento, estamos detectando as exigências enfrentadas pelos professores no mundo contemporâneo, para neste quadro, caracterizar as tensões entre as posturas adquiridas a partir da formação no âmbito da modernidade e as exigências da pós-modernidade. Trazemos as conclusões de uma pesquisa sobre a produção do professor, realizada na UFPR ${ }^{1}$, na qual buscamos novos olhares sobre seu trabalho no locus da sala de aula para identificar as dimensões e aspectos evidenciados pela prática pedagógica cotidiana, levando em conta as exigências de mudança expressas também nas prescrições das reformas e propostas educacionais oficiais. Para essa reflexão, consideramos a noção de habitus de BourdiEu, buscando elementos de análise da atuação/produção do professor no contexto da cultura escolar.

Estamos partindo de referências circunscritas ao âmbito de posições críticas $^{2}$ da educação, que comportam discernimentos em perspectivas da pósmodernidade. Reorientar o papel do professor face à mudança não significa que este deva adaptar-se às exigências mercantilizadas ou neoliberais das novas configurações sociais e econômicas. Buscamos na presente abordagem

${ }^{1}$ Referimo-nos aos resultados da pesquisa por nós realizada com alunos(as) do curso de Pedagogia, da disciplina de Currículos e Programas e de Especialização em Organização do Trabalho Pedagógico (1999 e 2000), complementada por Projeto de pesquisa desenvolvido pelo Prolicen (2001).

${ }^{2}$ Referimo-nos às posições críticas, no sentido de que postulam a compreensão da educação historicamente, a partir de seus condicionantes político-econômico-sociais e das relações de poder presentes na sociedade. 
desenredá-lo da profusão de exigências que lhe são feitas, situando as necessidades de sua atuação, formação e engajamento profissional hoje.

\section{Ser professor no contexto atual...}

Pode-se dizer que nunca foi tão difícil ser professor como nos dias de hoje. A trajetória da profissão docente tem estreita ligação com a história da educação escolar e com os impasses e desafios por ela enfrentados. A industrialização teve seus reflexos organizacionais empresariais, nos moldes taylorista-fordista refletidos no âmbito escolar, tirando do professor, em grande medida, a função de pensar/agir sobre o processo pedagógico, função que coube aos especialistas. A relação vertical dos órgãos oficiais educacionais ao propor reformas e novas propostas educacionais, vêm alijando o professor das discussões próprias da função. A profissão docente, nas últimas décadas, se depara com um processo de valorização/desvalorização, crítica e perda de identidade. Embora não nos detenhamos especificamente nessa trajetória histórica, consideramos, nos aspectos que nos propusemos a abordar, os reflexos desse processo. ${ }^{3}$

No que se refere à competência técnico-didática e científica, o professor veio construindo o conhecimento com o qual trabalha apoiando-se nos estatutos da modernidade que têm na ciência, a verdade absoluta, incontestável. Para ALVES \& GARCIA (2000), a educação sempre esteve ligada a um projeto, a um sentido e fica difícil para o professor detectar seu papel numa escola onde sua autoridade não é mais construída pela certeza de métodos e técnicas.

Para FURQUin, frente à mudança contínua e rápida que dirige nossas propostas de vida e trabalho, a grande preocupação do professor passa a ser a legitimidade da coisa ensinada, no que se refere ao seu valor educativo, consistência e interesse despertado. O trabalho a partir da cultura compreendida como herança coletiva e patrimônio intelectual e espiritual requer a transposição dos limites das comunidades particulares, o que coloca para a escola e para o professor novas conformações de trabalho e ultrapassagem de frontei-

${ }^{3}$ Ver para esse resgate histórico referências desta publicação: NóvoA, A. Cap. I, 1995 ; bueno, B. O.; Catani, D. B. e sousa, C. P., 1998 e almeida, M. I., 1999. 
ras. -“Que é pois que, nos conteúdos vivos da cultura, nas significações que atualmente têm poder de interpelar nossos pensamentos e de regular nossas existências, pode ser considerado como um valor educativo que justifique um determinado sistema de ensino?" (FORQUIN, 1993).

Em relação ao aluno, o acesso ao conhecimento se dá concomitantemente à influência da mídia (televisão, Internet, revistas, cinema, vídeos etc.) e das relações que se dão na sociedade, como os grupos de amigos, as tribos urbanas com valores específicos e maneiras peculiares de vestir, a música, o futebol, a igreja e outras. Na sociedade pós-moderna, a mudança de valores e significações, em que a própria destruição do homem também está posta, os professores sentem-se perplexos. Como redimensionar suas funções frente à validação de todas as formas de ser e estar na sociedade?

Para NóvoA (1995), a configuração do sistema de ensino mudou radicalmente e encontramo-nos, por um lado, perante uma autêntica socialização divergente: a de uma sociedade pluralista, com modelos de educação opostos e valores diferentes e contraditórios e, por outro, a da diversidade própria da sociedade multicultural e multilíngue. O caráter unificador no campo cultural, lingüístico e comportamental em que se afirmava a escola, obriga hoje a uma ação diversificada na atuação do professor.

As necessidades de mercado apontam para a diminuição crescente de mão-de-obra em função da evolução da informatização e robotização industrial, causando desemprego em larga escala, além da altíssima concentração de renda restringindo oportunidades de vida e trabalho. (ALVES \& GARCIA, 1993). Somam-se ao desemprego, a violência e a falta de perspectivas pressionando o professor a encontrar respostas que ultrapassam as suas possibilidades de formação.

ESTEVE (Apud. NóvOA, 1995, p. 95) descreve o que chama de mal-estar docente, como o conjunto de reações dos professores, como grupo profissional que se desajusta frente à mudança social. Destaca fatores de primeira ordem, que incidem diretamente sobre a ação do professor na sala de aula (imposições administrativas, isolamento etc.), provocando emoções negativas, e de segunda ordem, as condições ambientais do contexto onde exerce a docência (falta de tempo, material adequado, excesso de alunos, condições salariais precárias), com ação direta sobre a motivação e desempenho na função.

O esforço da profissão neste contexto complexo aponta um grupo de profissionais que começa a demonstrar visíveis sinais de esgotamento. MASLACH e JACKSON (Apud CODO, Wanderley, 1999, p. 238) apresentam a chamada síndrome de burnout (síndrome da desistência), que é definida como uma 
reação à tensão emocional crônica gerada pelo contato direto e excessivo com outros seres humanos preocupados e com problemas. Tal processo de exaustão emocional, despersonalização e desistência da profissão, mesmo em atividade, já está presente em nossas escolas, ameaçando os objetivos da função docente e da própria educação escolar.

Embora estejamos frente a dados tão preocupantes, sabemos que há um grande contingente de professores que permanece ativo em sala de aula, incluindo os que conservam seu ímpeto de luta e ideal, o que reafirma a urgência de um trabalho de reorganização e suporte à profissão docente. Para caracterizar os desafios e possibilidades da função no processo complexo analisado até aqui, procuraremos considerá-la a partir da sua natureza, buscando aquilo que lhe é próprio.

\section{A natureza do trabalho do professor}

A educação é um fenômeno próprio dos seres humanos, sendo que a prática da educação existiu antes que tivéssemos um conhecimento formalizado sobre a mesma. Caracterizar a função pedagógica nos leva a voltar o olhar à função do pedagogo na Grécia antiga, em que significava literalmente a condução da criança por um escravo ao ensino. O 'ser pedagogo' passa a significar a condução ao saber, à cultura, função transposta posteriormente ao preceptor, ao educador. Através do tempo, a escola passa a ser o local institucional do ensino e da prática pedagógica. Cabe à escola a identificação dos elementos culturais que precisam ser assimilados pelos indivíduos, concomitantemente à descoberta das formas mais adequadas para atingir este objetivo (SAVIANI, 1991, p. 19).

Para dimensionar esse processo, evocamos o conceito marxista de trabalho, no qual o homem, ao agir e transformar o objeto sobre o qual atua, o transforma, transformando-se a si mesmo (VASQUEZ, 1977, p. 35). MARX caracteriza esse processo como práxis, processo em que o pensamento humano adquire verdade objetiva, a partir não da teoria, mas da prática (Apud SACRISTÁn, 1999, p. 24).

A práxis se expressa no trabalho pedagógico como ação, reflexão e transformação do sujeito que dele participa, considerando a natureza não material da educação escolar, isto é, a produção de idéias, símbolos, hábitos, atitudes, 
habilidades. Nesse processo humano-social, a aula é momento privilegiado de transmissão/assimilação, em que algo permanecerá para além do ato de aprender. A transformação do aluno passa dessa forma pela sua condição não passiva e humana. Ele tem um papel no processo de produção pedagógico e dele participa na condição de produtor e co-produtor (PARO, 1993, p. 103). Essa mesma condição, na troca e interação com o educando, é exercida pelo professor. $\mathrm{O}$ aluno como objeto de trabalho e como reflexo do contexto atual, é elemento que também norteia o desenvolvimento do seu trabalho e o conhecimento pedagógico que dele decorre, levando-o a recriá-lo na prática cotidiana. A ação do professor nessa perspectiva deve ser vista como política cultural, em que o professor é intelectual que se transforma e transforma seus alunos. (GIROUX, 1997, p. 136).

A natureza da educação formal consiste, assim, na responsabilidade de ter que transmitir e perpetuar a experiência humana considerada como cultura, como significado comunicável, que se cristaliza em saberes cumulativos, em sistemas de símbolos, em instrumentos aperfeiçoáveis, em produções admiráveis (FORQUIN, 1993, p. 16). É pela e na educação, e também por meio do trabalho paciente e continuamente recomeçado de uma tradição docente, que a cultura se transmite e se perpetua.

Cabe ressaltar também que o ensino, como ofício, é um conjunto de tarefas técnico-didáticas, decorrentes do conhecimento científico e de relações humanas estruturadas de determinada maneira na escola. O planejamento individual e coletivo, o contato com pais, participação de comissões, reuniões, elaboração de relatórios e informes escritos etc. engendra um mosaico de atividades que, na vivência de cada profissional, se organiza e ganha significado.

Estamos considerando que o professor, ao exercer seu trabalho, vivencia todos esses aspectos, tanto na sua formação como na sua trajetória profissional, precisando, por isso, dominar o ato de ensinar e formar, que permanece como natureza deste trabalho, com todos os envolvimentos aí implicados.

A ordem dita natural da educação formal no entanto, considerada no seu sentido histórico, em suas configurações na sociedade globalizada, interferiu na natureza da profissão docente engendrando complexas relações. Assim, categorias como tempo e espaço podem ser distorcidas pelo "progresso" tecnológico, interferindo no apriorismo natural da ética e estética humanas, presentes na função pedagógica, que passam a ser alteráveis, mutáveis, não tão naturais assim. Podemos pensar então que a natureza da profissão docente expressa uma crise a ser definida em suas causas a partir do próprio processo sociocultural vivido pelos professores. 
Esclarecer as finalidades assumidas para a escolarização e descobrir como são vivenciadas na prática docente é penetrar nas razões mais profundas da ação da educação formal institucional. Nada, nem o pensamento cientificista e sua especialização fragmentária, é mais importante do que a função para a qual acreditamos que as escolas existem, já que sua razão de ser tem a ver com um projeto cultural e político. Os professores são principalmente agentes culturais e suas posições, aquilo que desenvolvem e acreditam que devem difundir, são determinantes para suas práticas (SACRISTÁN, 1999, p. 148).

Alerta HARGREAVES para dois movimentos que acarretam conseqüências no trabalho dentro e fora de sala de aula, interferindo nestas conformações culturais:

- a profissionalização, que ressalta as mudanças no rol de atividades do docente e suas ampliações de forma mais complexa, circunscritas ao campo da competência técnico-didática e científica: o domínio dos conteúdos e métodos das áreas de atuação, e as vivências de papéis de liderança, contribuição em trocas de experiências, trabalhos compartilhados, colaboração em decisões e outras;

- a intensificação do trabalho docente, que se refere à deterioração e desprofissionalização da função, que consiste no trabalho cotidiano como espaço de opções pedagógicas, mas que não tem sido considerado como emissão de juízo sobre o que parece mais adequado trabalhar pedagogicamente. O descaso para com o trabalho cotidiano do professor, passa a ser um equívoco a ser reavaliado pelos pesquisadores e no âmbito das escolas, em programas de formação continuada e em serviço, já que os sentidos da mudança estão nele expressos.

Uma questão prevalece no processo sociocultural da profissão docente: refletir sobre o que tem representado a idéia de necessidade de mudança para os professores.

\section{Necessidade de mudança e a tensão entre a modernidade e pós-modernidade}

Os rumores da mudança podem ser detectados em vários países, o que mostra que esta acontece como um fenômeno global, sendo que as pautas 
contemporâneas de reforma educativa são sistêmicas e estão interconectadas. Esse fato exige a necessidade de uma análise significativa e realista da mudança, o que requer mais do que um simples balanço de vantagens e inconvenientes das reformas e das formas de gestão escolar.

As reformas educacionais surgem num momento de desencanto e ceticismo quando a sociedade deixou de acreditar na educação como a promessa de futuro melhor. Para SACRISTÁn (1998), as reformas encerram a idéia de mudança, no sentido de que se deposita na escola a possibilidade de definir novos rumos para a educação na busca de melhoria de resultados. Não basta constatar a mudança ou a necessidade dela para justificar as tentativas de reforma recentes no ensino.

Uma reflexão fundamental à idéia de necessidade de mudança nas direções do trabalho do professor encontra-se no fato de que as estruturas básicas da escolarização se estabeleceram em outros tempos, com fins anacrônicos, enquanto a sociedade muda para uma era pós-industrial, pós-moderna. Para HARGREAVES, nossas escolas e professorado permanecem apegados a hierarquias rígidas, disciplinas isoladas, departamentos separados e estruturas de carreira antiquadas.

Caracterizando a tensão da necessidade de mudança na função docente, podemos divisá-la então entre estas duas forças poderosas: a modernidade $e$ a pós-modernidade, assim caracterizadas por HARGREAVES (1994, p. 36-37):

A modernidade expressa-se como força social impulsionada pela fé no progresso científico racional, no triunfo da ciência e da tecnologia sobre a natureza e na capacidade de controlar e melhorar a condição humana por meio da aplicação desses conhecimentos. Do ponto de vista econômico, a modernidade começa a separar a família e o trabalho pela concentração racional da produção no sistema fabril e culmina com os sistemas de produção em massa, o capitalismo, o monopólio e o socialismo estatal como formas de incrementar a produtividade. Do ponto de vista político, o controle mantémse no centro, na gestão das decisões, no bem-estar social, na educação, na intervenção e regulamentação econômica. A organização se reflete na burocracia disposta em hierarquias e segmentada por especialidades. Na dimensão pessoal, prevalece o sistema, a ordem mas também um certo sentido de identidade coletiva e de pertença a um grupo. Tal ordem trouxe alienação e falta de sentido às vidas individuais.

A pós-modernidade, para alguns autores, inicia nos anos 60 e situa-se filosófica e ideologicamente em princípios muito diferentes. Os avanços nas telecomunicações, na rápida divulgação de informações, questionam antigas certezas ideológicas e filosóficas, à medida que as pessoas constatam que 
existem outras formas de viver. Os descobrimentos científicos sobre coisas que afetam o cotidiano (aquecimento global, a proteção contra o câncer, o ensino eficaz etc.) são superados por outros novos e a uma velocidade cada vez maior. No declínio do sistema fabril, as economias pós-modernas se estruturam em torno da produção de mais bens pequenos do que grandes, serviços, manufaturas, informações e imagens... Verifica-se como princípio econômico motor a acumulação flexível, uma vez que tudo depende de respostas rápidas às demandas locais mutantes do mercado.

Considerando o ponto de vista político e organizacional, a necessidade de respostas rápidas se reflete na descentralização de decisões e menor demarcação de papéis e limites. Do ponto de vista pessoal, o mundo pós-moderno dá lugar a uma crescente potenciação pessoal, mas sua falta de estabilidade pode provocar crises e isolamento nas relações interpessoais, já que estas necessitam de tradições que garantam sua segurança e continuidade.

O mundo pós-moderno é rápido, comprimido, complexo e inseguro. A incerteza ideológica se opõe à tradição judaico-cristã, na qual se baseiam muitos sistemas escolares, suscitando crise de identidade e de finalidades em relação a novas missões. A busca de formas de decisão mais cooperativas está apontando para caminhos mais colaborativos, ainda questionados por líderes escolares que temem perder seu poder.

No conflito caracterizado em posições tão diferenciadas, está situada a restruturação educativa, como exercício de prudência e construção, na qual se ganhará ou se perderá a batalha pela profissionalidade docente.

\section{Investigando os sentidos da mudança no trabalho do professor}

Para ampliar essa reflexão e buscar responder questões que viemos até agora levantando, trazemos alguns resultados da pesquisa que desenvolvemos na Universidade Federal do Paraná desde 2001, no curso de Pedagogia, na matéria de Currículos e Programas, na qual procuramos investigar a prática dos professores, verificando seu trabalho nas áreas de ensino frente às questões da atualidade.

Esse trabalho, que teve procedimentos do estudo etnográfico, não significou apenas colher depoimentos de sujeitos falando de si mesmos e de suas práticas cotidianas, buscou, sim, observação participante, momentos de tro- 
cas, conversas informais e posterior análise de documentos curriculares da escola e discussão dos códigos e opções apresentados pelos professores (ANDRÉ, 1995, p. 27).

Utilizamos uma entrevista com questionário semi-estruturado e observação nas escolas e em classe pelos grupos de alunas da matéria. Cada grupo pesquisou uma área de ensino a partir da observação e contato com um professor das escolas públicas municipais ou estaduais de Curitiba. As perguntas versavam sobre a formação do professor e sua experiência profissional, preocupações com a formação dos alunos e alunas hoje, além de questionar a metodologia de trabalho, avaliação, material utilizado, auxílio que recebem da supervisão/orientação pedagógica, impressão sobre as Propostas Pedagógicas atuais, problemas encontrados no trabalho curricular e entraves para o exercício da função.

Em 14 grupos de alunos(as), foram observadas as atividades de 14 professores. A pesquisa mostrou que a maioria dos professores entrevistados tem curso superior, e que $70 \%$ são formados na área de ensino que atuam e poucos possuem especialização; outros não têm formação na área e nem sempre possuem formação didático-pedagógica. Sua formação se dá na prática cotidiana e no contato com outros professores da área, da escola e ao longo da carreira.

Algumas constatações puderam ser feitas, apontando para atividades/atitudes e mudanças nas posturas e métodos adotados no trabalho que desenvolvem:

- os professores observam dados positivos dos anos anteriores na disciplina que trabalham, para planejar o trabalho curricular atual;

- os professores, em geral, se preocupam com o poder da mídia e utili zam dados e materiais veiculados nos meios de comunicação para desenvolver os conteúdos curriculares (vídeo, filmes sobre assuntos trabalhados, computador, revistas etc.);

- a questão ambiental (degradação, extinção de animais, descaso do homem para com os rios e parques, etc.) está definitivamente posta no trabalho curricular, a ponto de que para $80 \%$ dos professores a mesma deve ser constitutiva e intercessória entre todas as áreas;

- alguns professores não mais conseguem abordar assuntos de forma estanque, sendo necessário no desenvolvimento dos conteúdos o uso de vários tipos de informações e conhecimentos (rede) que interferem no desenvolvimento dos assuntos trabalhados;

- há uma preocupação bastante significativa com a ética nas atividades desenvolvidas, em que as fraudes em diversas situações de vida social fazem com que o professor procure abordar questões que ocorrem com o consumidor, direitos do cidadão, etc. 
- parte dos professores selecionam e confeccionam materiais, quando não têm recursos na escola ou não sentem a colaboração da equipe pedagógica como gostariam;

- Alguns professores se debruçam com mais afinco nas questões da formação do aluno na atualidade, trazendo reflexões e metodologias, que tentam com dificuldade compartilhar.

Na segunda fase da pesquisa, em 2001, pelo Prolicen, elegemos três escolas da rede pública e realizamos uma investigação mais próxima do cotidiano do professor, sendo que outras conclusões foram acrescidas às anteriores:

- parte dos professores está buscando elaborar novos projetos, a partir das brechas abertas pelas propostas das Secretarias de Educação, em que se inclui um aumento mínimo de salário;

- os professores sentem falta de cursos e espaços de discussão (não há tempo no calendário escolar) sobre questões relacionadas ao trabalho pedagógico em suas áreas de ensino, no contexto atual;

- ficaram evidenciadas as dificuldades de transição da Proposta de Currículo Básico 4 para a Proposta de Parâmetros Curriculares cujos pressupostos, intenções, metodologias e avaliação não estão claros aos professores, inclusive no que se refere às Concepções, Temas Transversais e ao processo de Ciclos de Aprendizagem;

- onde há maior clareza e envolvimento na proposta curricular da escola e assuntos do processo pedagógico (postura democrática da Equipe Pedagógica e Direção), a produção do professor é mais evidente, há maior motivação e empenho para o trabalho.

As possibilidades de leitura da realidade cotidiana dos professores e das inovações presentes em um grupo significativo comprovam claramente seu potencial criativo e reflexivo. Percebe-se um grupo de professores que catalisa os processos de mudança, demonstrando ser porta-voz de novas posturas e de seus pares, independentemente das áreas em que atuem. As novas metodologias e inovações são, pelos depoimentos colhidos, frutos das necessidades e interesses que emergem na sala de aula a partir da realidade social, ambiental e humana que professor e aluno vivenciam. Esse grupo sente necessidade de discutir suas idéias e de compartilhar com os colegas suas reflexões, mas sente-se pressionado pela falta de tempo. O outro grupo que é significativo,

\footnotetext{
${ }^{4}$ Proposta curricular oficial que vigorou no Estado do Paraná desde 1990.
} 
mostra-se consciente de novas necessidades do ensino, mas parece inseguro quanto às novas concepções e direcionamentos prescritivos, recorrendo pouco a essas orientações. Um terceiro grupo resiste à idéia de mudança ou novas propostas, declarando-se "tradicionais", agindo da forma que consideram correta, revelando confiança no próprio trabalho. Este é um dado revelador e positivo por um lado, e por outro, é preocupante na medida em que pode representar também acomodação e isolamento.

Para WidEMAN (Apud haRgReAVes, 1994, p. 38) na mudança, a prática muda, antes de convicções impostas: as mudanças vindas "de cima", afirma o autor, não adentram o núcleo de como o aluno aprende, embora tenham força de lei.

O professor da rede pública de Curitiba tem atuado a partir de Propostas Político-Pedagógicas consistentes, mas afirma não dominar as concepções e metodologias nelas impressas, e fala da sua preocupação ao verificar dificuldades complexas de aprendizagem nos alunos, procurando em profissionais das áreas de ensino e através de sua experiência e interpretação o domínio científico e técnico didático de que necessita (CAmpos, 1993). Atualmente, pode-se dizer que as propostas de mudança que emanam do MEC centram-se nos Parâmetros Curriculares e na Lei de Diretrizes e Bases e suas normatizações posteriores, com prescrições e instruções em grande medida fundadas na lógica do mercado, descaracterizam o curso de Pedagogia e criam novos espaços institucionais de formação docente. Tais propostas, distantes da prática real da escola brasileira, não têm mostrado historicamente, e ainda hoje, reflexos positivos na resolução dos problemas da educação escolar. ${ }^{5}$

Na prática das escolas, embora com as dificuldades que pudemos constatar, pode-se detectar os reflexos dessas prescrições, mas com adaptações elaboradas por boa parte dos professores, num processo de revisão e moldagem do currículo que aplicam. Nessa moldagem pode-se visualizar o currículo real, aquele que realmente está em ação na escola, engendrado pela atuação do professor (SACRISTÁN, 1998, p. 105-106).

Quando o professor afirma utilizar dados, atividades e procedimentos dos anos anteriores para o trabalho atual, podemos evocar aqui a noção que BOURDIEU define como habitus e que se desenvolve como "um sistema de disposições duradouras e transponíveis, que integram experiências passadas". Estas são transferidas a experiências do cotidiano e vão compondo o arsenal

\footnotetext{
${ }^{5}$ Ver os artigos de SHEIBE e RIBEIRo na 3 . $^{\text {P }}$ Parte desta publicação.
} 
histórico-profissional do professor (Apud PERRENOud, 1996 p. 39). ${ }^{6}$ Para SACRISTÁN (1998), o habitus funciona como uma espécie de ordem impessoal de autoria coletiva, que dirige e regula ações futuras, de formas a permitir o alcance de determinados fins, sem que se precise planejar a intenção de cada ação, as opções a serem tomadas frente a cada dilema do cotidiano escolar.

Essas estruturas funcionam tendendo a assegurar sua própria sobrevivência diante das transformações que lhe forem solicitadas pelas novas circunstâncias, selecionando, rejeitando ou evitando informações e ações contrárias à sua lógica. Os esquemas de ação compartilhados pelos professores dão estabilidade a práticas coerentes e constantes no tempo, dotando de congruência as ações individuais entre si, diferenciando estilos e práticas de ação, garantindo continuidade. É importante constatar também que o efeito estabilizador do habitus não nega o processo contínuo de novidades frente a acontecimentos provocativos atuais e que não admitem velhas respostas (SACRISTÁN, 1999, p. 83-84).

A participação dos professores na mudança educativa é vital e não basta, portanto, que adquiram novos conhecimentos sobre concepções, métodos e técnicas didáticas. Os professores, mais que aprendizes técnicos, são aprendizes sociais. O conhecimento do desejo do professor parece mostrar com mais verdade o que se deve mudar ou conservar e este é fundado em uma trajetória profissional. A experiência dos professores de cooperação informal e espontânea poderá esvaziar-se, no entanto, ao se sujeitar ao excessivo controle administrativo que escamoteia o verdadeiro curso de sua atuação nas situações de mudança.

É fundamental reafirmar, ainda, que o saber docente não é formado apenas da prática, mas é nutrido pelas teorias da educação. O professor desenvolve-se como intelectual crítico no próprio processo de profissionalização, nos cursos de aperfeiçoamento e na prática cotidiana, quando incorpora a análise do âmbito escolar no contexto mais amplo, buscando respostas para o trato da desigualdade e diversidade com que trabalha hoje. A possibilidade de reflexão que observamos nos reporta à concepção Gramsciana: "o problema da

${ }^{6}$ Estamos recorrendo a BOURDIEU como teórico que, ao trazer a visão sobre as instituições que respondem adaptando-se à ordem da estratificação social, mostrou que saberes têm uma história, aprendizagens têm contexto e professores têm ancoragens sociais como função da sociologia (LAHIRE, 2002). Para Bourdieu, a transformação (mudança) não é um objeto material, mas a orquestração do conjunto das práticas (PERRENOUD, 1996, p. 42). Ver também nas Referências: CATANi, A. M.; CATANi, D. B. e PEREIRA, G. R. de M. , 2001; LAhire, B., 2002, p. 45-46 e PerRenoud, 1997, p 38-43. 
criação de uma nova camada intelectual consiste em elaborar criticamente a atividade intelectual que existe em cada um em determinado grau de desenvolvimento" (GRAMSCI, 1985, p. 8). Tal concepção confere à função docente um posicionamento reflexivo, crítico e político que compõe seu próprio papel social (GIROUX, 1997) de também criar novos intelectuais.

Reconhecendo que no processo das reformas o poder e o conhecimento circulam de forma desigual, recorrer às novas visões da antropologia, sociologia e etnografia representa uma grande contribuição à pesquisa e análise do discurso e da prática pedagógica, não mais a partir da cultura dominante. Assim, pensa-se poder visualizar o professor não mais como dono do saber formal, mas em um movimento de trocas culturais com os alunos, com seus pares e com a comunidade. Por outro lado, não é mais possível vê-lo alijado das reflexões sobre o processo político-pedagógico do contexto em que atua, respondendo passivamente a propostas de mudança impostas e não discutidas.

\section{Aspectos e dimensões conclusivas}

As reflexões que fizemos tiveram o objetivo de buscar a idéia de mudança, na perspectiva de considerá-la expressa de alguma forma nas exigências do contexto atual, nas reformas e prescrições oficiais, que colocam o professor, no embate cotidiano da função, frente a dilemas e desafios que demandam novas configurações de trabalho.

Na luta fundamental de quem foi formado e atua a partir dos pressupostos da modernidade, frente ao colapso das certezas morais, da derrubada de antigas missões e de certezas científicas, o professor apresenta posições entre a resistência e a produção.

Consideramos que o professor, ao vivenciar os múltiplos saberes pedagógicos, desenvolve sua competência científica e técnico-didática para dominar o ato de ensinar e formar, que permanece como natureza deste trabalho, com todas as suas implicações. Esses campos de ação docente, vividos na sua formação e trajetória profissional, não podem prescindir, no entanto, do campo humano social sua contribuição pessoal e cultural.

O que o aluno aprende passa para além da sala de aula, o que confere ao trabalho do professor o peso de sua contribuição aos indivíduos. Pudemos vê-lo, por isso mesmo, como agente produtor de sua prática e função, a partir das necessidades do aluno. 
Constatamos na pesquisa realizada na UFPR indicadores claros de que um grupo significativo catalisa as tentativas de mudança e outro que se mostra preocupado com as novas propostas, seguindo caminhos que sempre trilhou, sem a preocupação de inovar. Esses grupos encontram-se imobilizados, não pela ação, mas pela falta de interlocução e principalmente de tempo; o grupo que se mostra resistente, e se diz "tradicional", mostra saber os porquês dessa atitude. Aliás, a resistência a várias situações de imposição administrativa permeia a ação de todos e na maioria das vezes demonstra bom senso e razões justas. Há diferentes formas e tempos de captação do novo, e este novo circula entre a totalidade dos grupos de docentes em maior ou menor intensidade e interesse.

$\mathrm{Na}$ pesquisa realizada, os professores referem-se às incertezas de formar o homem no contexto atual, no qual precisam responder às questões do conhecimento e àquelas da formação: éticas e valorativas. Pudemos ver o professor preocupado ao trabalhar as questões da degradação ambiental, questões éticas em situações cotidianas de compra e venda, de trabalho etc., os problemas da sexualidade, e outros, num processo em que os conteúdos curriculares tomam novas conformações. Sentem que as noções não podem mais ser trabalhadas de forma fragmentada e utilizam passo a passo a rede de informações que circunda o conhecimento hoje e não está só nos livros e programas, mas na mídia, nos acontecimentos mundiais, nas descobertas científicas, em todas as formas de expressão. Apontam, portanto, para novas formas de ver e de passar o conhecimento para o aluno que temos hoje.

Os professores, todavia, não acreditam em suas possibilidades de contribuir cientificamente para construir conhecimento sobre o ensino, e mesmo não dispõem de caminhos formais, métodos para que seus conhecimentos se tornem parte da literatura pedagógica (SMITH; LYTLE, apud BUENO, CATANI; SOUZA, 1998, p. 9). A mobilização dessa produção e seus sentidos depende hoje de mudanças nas políticas de pesquisa e de aperfeiçoamento profissional, que, reorganizadas sob novos parâmetros, podem se constituir em novas possibilidades de formação geral, continuada e em serviço.

$\mathrm{Na}$ análise realizada, percebemos que o habitus, como sistema de ações próprios do professor e da instituição escolar, emerge das trajetórias profissionais, das necessidades do contexto social, do perfil dos alunos, da prática cotidiana, dos cursos de formação e aperfeiçoamento. Os professores como agentes culturais, em suas formas de ver, suas crenças sobre o educando e sobre a ação de educá-lo, apresentam informações substanciais, a partir de suas interpretações e produções, sobre o que consideram como fins da educação escolar hoje. Por outro lado, a cultura como significação na sociedade 
aparece também como forma niveladora de opiniões e na positividade das trajetórias docentes e suas práticas cotidianas. É preciso observar o movimento da acomodação, quando aqueles que são os protagonistas do processo pedagógico estão, em grande medida, alijados das discussões mais substantivas da educação.

No processo de produção e moldagem curricular, em que os professores desenvolvem um trabalho paralelo ao das propostas oficiais, pudemos constatar que não é mais possível pensar as propostas pedagógicas atuais sem a análise do processo da mudança engendrado pelo professor, sob pena de que se constituam em planos sem respostas à sua prática real.

Há iniciativas que buscam valorizar e respeitar o progresso profissional do professor, mas a forma como têm sido apresentadas acaba por encaixá-las em modelos mecanicistas. Para HARGREAVEs (1994), o tempo administrativo não é o tempo da mudança e os instrumentos administrativos podem ameaçar a vontade de ensinar, eliminando seu motor. A produção inovadora e adequada do professor hoje pode ser impulsionada ou sufocada. Assim, para impulsionar os novos movimentos da função docente, há que se gestionar tempo e espaço nos sistemas educacionais, o que não quer dizer restringir liberdade.

O professor vem travando diariamente uma luta entre o novo e o velho, o estabelecido e o não-reconhecido, decidindo entre o que deve ou não ser alterado (ALONSO, 1999, p. 16), mostrando os sentidos e necessidades da mudança. Frente à validação de todas as formas de ser e estar na sociedade pósmoderna, na qual a própria destruição do homem também está posta, os professores sentem-se perplexos. Lembramos aqui, novamente, a retomada da idéia de natureza do trabalho pedagógico, daquilo que é próprio da função docente e que tem nas idéias de construção, condução à cultura, positividade e emancipação do ser humano sem distinção, a sua dimensão fundamental e própria na redefinição de novas posições frente à mudança.

Ao finalizar, lembramos a preocupação de HARGREAVES de tirar o professor do isolamento provocado pela sociedade pós-moderna, trazendo-o para reflexões e compartilhamento, discussão de novos projetos, em grupos que poderão ser formados em colaboração, com equipes pedagógicas e pesquisadores, entre escolas próximas e sob o apoio das universidades e secretarias de educação.

As vozes, experiências e opiniões dos professores são os elementos vitais da própria mudança. Valorizá-las lhes devolve a função intelectual que lhe é própria e leva à reinterpretação e desvelamento das novas dimensões da função e formação docente na atualidade. Essa é também a possibilidade de ensino qualificado aos alunos que freqüentam a maioria de nossas escolas hoje. 


\section{REFERÊNCIAS}

ALMEIDA, M. I. O sindicato como instância formadora de professores: novas contribuições ao desenvolvimento profissional. São Paulo, 1999. Tese (Doutorado em Educação) - Departamento de Metodologia do Ensino, Universidade Estadual de São Paulo.

ALONSO, M. Formar professores para uma nova escola. In: QUELUZ, A. G. O trabalho decente: teoria \& prática. São Paulo: Pioneira, 1999.

ALVES, N.; GARCIA, R. (Orgs.). O sentido da escola. Rio de Janeiro: DP\&A, 2000.

ANDRÉ, M. E. D. A. Etnografia da prática escolar. São Paulo: Papirus, 1995.

BOURDIEU, P. Razões práticas sobre a teoria da ação. Campinas: Papirus, 1996.

BUENO, B. O.; CATANI, D. B.; SOUZA, C. P. A vida e o oficio dos professores: formação contínua, autobiografia e pesquisa em colaboração. São Paulo: Escrituras, 1998.

CAMPOS, R. C. As políticas educacionais para o município de Curitiba no período de 1982-1993 e a qualidade da escola pública: limites, possibilidades e perspectivas. Curitiba,1993. Dissertação (Mestrado em Educação) - Universidade Federal do Paraná.

CATANI, A. M.; CATANI, D. B.; PEREIRA, G. R. de M. As apropriações da obra de Pierre Bordieu no campo educacional brasileiro através de periódicos da área. Revista Brasileira de Educação, Anped, Autores Associados, n. 17, maio/jul. 2001.

CODO, W. (Coord.). Educação: carinho e trabalho. Petrópolis: Vozes, 1999.

COSTA, M. V. Discutindo a escola básica em tempos de neoliberalismo: uma conversa introdutória. In: COSTA, M. V. Escola básica na virada do século: cultura, política e currículo. São Paulo: Cortez, 1996.

ESTEVE, J. M. Mudanças sociais e função docente. In: NÓVOA, A. (Org.). Profissão professor. Portugal: Porto Editora, 1995.

FORQUIN, J. C. Currículo e cultura. In: . Escola e cultura. Porto Alegre: Artes Médicas, 1993.

GIROUX, H. Os professores como intelectuais. Porto Alegre: Artes Médicas, 1997.

GRAMSCI, A. Os intelectuais e a organização da cultura. Rio de Janeiro: Civilização Brasileira, 1985.

HARGREAVES, A. Professorado, cultura y póstmodernidad. Madrid: Morata, 1994.

LAHIRE, B. Reprodução ou prolongamentos críticos? In: Dossiê "Ensaios sobre Pierre Bourdieu", Revista Educação \& Sociedade, ano 23, n. 78, abr. 2002. 
NÓVOA, A.(Org.). Profissão professor. Portugal: Porto Editora, 1995.

PARO, V. H. A natureza do trabalho pedagógico. Revista da Faculdade de Educação da USP, São Paulo, v. 19, n. 1, jan./jun. 1993.

PERRENOUD, P. A prática pedagógica entre a investigação e o bricolage. In: PIMENTA, S. Formação de professores-saberes da docência e identidade do professor. Revista da Faculdade de Educação da USP, São Paulo, v. 22, n. 2, p. 72-89, jul. 1996.

SACRISTÁN, J. G. O currículo: uma reflexão sobre a prática. 3. ed. Porto Alegre: Artes Médicas, 1998.

; GOMES, A. .I. P. Compreender e transformar o ensino. 4. ed. Porto Alegre: Artes Médicas, 1998.

. Poderes instáveis em educação. Porto Alegre: Artes Médicas, 1999.

SAVIANI, D. Pedagogia histórico-crítica: primeiras aproximações. Polêmicas do nosso tempo. São Paulo: Cortez, 1991.

VASQUES-MENEZES, I. O que é burnout? In: CODO, Wanderley (Coord.). Educação: carinho e trabalho. Petrópolis: Vozes, 1999.

VASQUES, A. S. Filosofia da praxis. 2. ed. Rio de Janeiro: Paz e Terra, 1977.

Texto recebido em 26 fev. 2004

Texto aprovado em 29 ago. 2004 